This is a postprint version of the following published document:

D. García-González, A. Rusinek, T. Jankowiak, A. Arias. Mechanical impact behavior of polyether-ether-ketone (PEEK). In: Composite Structures, v. 124, (June 2015), pp. 88-99.

https://doi.org/10.1016/j.compstruct.2014.12.061

(C) 2015 Elsevier Ltd All rights reserved

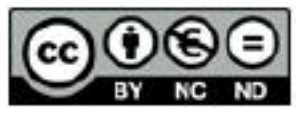

This work is licensed under a Creative Commons Attribution-NonCommercialNoDerivatives 4.0 International License. 


\title{
Mechanical impact behavior of polyether-ether-ketone (PEEK)
}

\author{
D. Garcia-Gonzalez ${ }^{\mathrm{a}}$, A. Rusinek ${ }^{\mathrm{b}}$, T. Jankowiak ${ }^{\mathrm{c}}$, A. Arias $^{\mathrm{a}, *}$ \\ a Department of Continuum Mechanics and Structural Analysis, University Carlos III of Madrid, Avda. de la Universidad 30. 28911 Leganés, Madrid, Spain \\ b Laboratory of Mechanics, Biomechanics, Polymers and Stuctures, National Engineering School of Metz, 1 route d'Ars Laguenexy. CS 65820 57078 METZ Cedex 3, France \\ 'Institute of Stnuctural Engineering. Poznan University of Technology. Piotrowo 5, Poznan, Poland
}

Keywords:

Biomaterials

Impact

Failure mode

Perforation

Polyether-ether-ketone

\begin{abstract}
This paper deals with the mechanical behavior of polyether ether ketone (PEEK) under impact loading. PEEK polymers are the great interested in the field of medical implants due to their biocompatibility. weight reduction, radiology advantage and 3D printing properties. Implant applications can involve impact loading during useful life and medical installation, such as hip systems, bone anchors and cranial prostheses. In this work, the mechanical impact behavior of PEEK is compared with Ti6Al4V titanium alloy commonly used for medical applications. In order to calculate the kinetic energy absorption in the impact process, perforation tes have been conducted on plates of both materials using steel spheres of $1.3 \mathrm{~g}$ mass as rigid penetrators. The perforation test covered impact kinetic energies from $21 \mathrm{~J}$ to $131 \mathrm{~J}$. the equivalent range observed in a fall, an accidental impact or a bike accident. At all impact energies, the ductile process of PEEK plates was noted and no evidence of brittle failure was observed. Numerical mod eling that includes rate dependent material is presented and validated with experimental data.
\end{abstract}

\section{Introduction}

The developments of new technologies and biocompatible materials have made it possible to replace more parts of the human body. Titanium alloy was generally used [1], but in recent years, following confirmation of biocompatibility $[2,3]$, the polymer poly ether ether ketone (PEEK) has been increasingly employed as matrix material for composites in trauma, orthopedic, dentals, spinal and cranial implants [4 6]. Implant applications of PEEK materials usually involve impact loading during medical installa tion and the useful life of prostheses, such as hip stems, bone anchors and cranial implants, Fig. 1. In this regard, cranial implants have experienced a significant evolution in the last decade in dif ferent aspects such as materials, method of fixation, and manufac turing process [5]. An important aspect to take into account is the load bearing capacity of these structural prostheses. Indeed, the implant must resist at different loading including those generated by a fall, an accidental impact or a bike accident. Mechanical impact process is a complex problem that includes dynamic behav ior, fracture, damage, contact and friction [7]. Therefore, impact loads can affect the structural response of materials used in prosthetic devices. In particular, the dynamic behavior of PEEK composites is highly influenced by the matrix properties due to its semi crystalline nature [8]. About this matter, interesting thermo mechanical phenomena have been reported for PEEK matrix $[9,10]$, including changes in crystallinity, deformation induced heating, macroscopic decolouration, high strain rate and large deformations associated with impact. The elastic properties of PEEK are relatively unaffected by rate effects at body tempera ture, which is below the glass transition [4]. However, the yielding and plastic flow behaviors are affected by strain rate at physiolog ical temperatures $[10,11]$. Additionally, adiabatic heating, associ ated with dynamic behavior of the impact process can induce rapid crystallization of PEEK a temperatures above glass transition [12].

In this regard, the impact behavior of PEEK has not been deeply studied in terms of kinetic energy absorption and failure under impact loading [11,13], and perforation tests have not been reported in the scientific literature.

In this work, perforation tests using rigid spheres have been conducted on plates of PEEK $450 \mathrm{G}$ and compared with Ti6Al4V titanium alloy, an alloy frequently used in medical applications. The perforation experiment covered impact kinetic energies from $21 \mathrm{~J}$ to $131 \mathrm{~J}$. A numerical approach, including the influence of strain rate and temperature, is presented and validated with exper imental data. This numerical model can be useful in the design of prosthetic implants subjected to impact loading. 


\section{Material}

A commercial plate of unfilled PEEK 450G, general purpose grade, with a density $\rho \quad 1300 \mathrm{~kg} \mathrm{~m}^{3}$ was purchased measuring $130 \times 130 \times 30 \mathrm{~mm}^{3}$. Mechanical and thermal properties are reported in Table 1 [14] in agreement with data published by other authors [11]. In addition to high strength and biocompatibility, unfilled PEEK has been used in both cervical and lumbar spinal cages and cranial implants with considerable clinical success $[5,6]$ and [15].

\subsection{Crystallinity}

PEEK is a two phase semi crystalline polymer, consisting of an amorphous phase and a crystalline phase. The crystalline content of injection molded PEEK in implants typically ranges from 30\% to 35\%, [4]. From differential scanning calorimetry (DSC) a degree crystallinity of $30 \pm 2 \%$ was calculated for PEEK $450 \mathrm{G}$ by integrating the melt endotherm and relating it to the literature value of $100 \%$ crystalline PEEK [16]. These data are in agreement with data reported by El Qoubaa and Ramzi [10] for PEEK 450G and with the calculated degree of crystallinity $\chi_{c}$, by Eq. (1):

$$
\left.\chi_{c} \frac{\rho_{c}(\rho}{\rho\left(\rho_{c}\right)}\right)
$$

where $\rho$ is the sample density, $\rho_{a} \quad 1260 \mathrm{~kg} \mathrm{~m}^{3}$, is the extrapo lated density of the pure amorphous phase and $\rho_{c} \quad 1400 \mathrm{~kg} \mathrm{~m}^{3}$, is the extrapolated density of pure crystalline phase [16]. Mechan ical properties of PEEK materials are influenced by the degree of crystallinity. Several authors have shown that increasing the degree of crystallinity can increase elastic modulus and yield strength while decreasing fracture toughness $[11,17,18]$. Different behaviors have been reported generating some controversy about the rela tionship between crystallinity and high strain rate. Hamdan and Swallowe [12] reported an increase in crystallinity of samples deformed by large strains under adiabatic conditions. However, Rae et al. [11] reported a decrease in crystallinity of all samples deformed by large strains.

\subsection{Strain rate and temperature sensitivity}

The PEEK 450G has been tested by Rae et al. [11] for different initial temperatures and strain rates. In this study a positive strain rate sensitivity was observed with the mechanical properties increasing with the strain rate. However, for a certain strain rate,
Table 1

Material properties of PEEK [14].

\begin{tabular}{lllll}
\hline Mechanical properties & & Thermal properties \\
\hline Elastic modulus (GPa) & 3.6 & Thermal conductivity $(\mathrm{W} / \mathrm{m} \mathrm{K})$ & 0.29 \\
Poisson's ratio & 0.38 & Specific heat $\mathrm{J} / \mathrm{kg} \mathrm{K}$ ) & 2180 \\
Density $\left(\mathrm{kg} / \mathrm{m}^{3}\right)$ & 1300 & Glass transition temperature (K) & 416 \\
Yield stress (MPa) & 107 & Melt transition temperature (K) & 616 \\
\hline
\end{tabular}

$\dot{\varepsilon}_{\text {transition }} \approx 0.1 \mathrm{~s}^{1}$, a thermal softening is observed and therefore, the process of plastic deformation has to be considered as adia batic, Fig. 2a. Concerning the temperature effect, a loss of ductility was observed when the initial temperature was lower than the room temperature $T_{0} 300 \mathrm{~K}$. Nonetheless, the ductility was retained with a strain level larger than $\varepsilon_{\text {low cemperature }}>0.2$. In addi tion, using experimental results published in [11], it was observed that the material behavior was still ductile for a temperature higher than $T_{0}>413 \mathrm{~K}$, Fig. $2 \mathrm{~b}$, knowing that the glass tempera ture is equal to $T_{g}>416 \mathrm{~K}$. It was also demonstrated that PEEK behavior was more brittle under tensile loading at low tempera ture compared with compression loading [11], with a failure strain level lower than $\varepsilon_{\text {failure }}^{\text {tension }}<0.1$ at $223 \mathrm{~K}$. Overall, the temperature sensitivity and the strain rate sensitivity are similar under tension and compression. The two major parameters under dynamic load ing have been defined. The values for the strain rate and tempera ture sensitivity are respectively equal to $m \quad \partial \log \sigma / \partial \log \dot{\varepsilon} \approx 0.46$ and $v \quad \partial \sigma / \partial T \approx 0.63 \mathrm{MPa} \mathrm{K}^{1}$. In dynamic loading, for a strain rate close to $\dot{\varepsilon} \approx 3000 \mathrm{~s}^{1}$, the temperature sensitivity is equal to $v \partial \sigma / \partial T \approx 0.71 \mathrm{MPaK}^{1}$.

\section{Experimental impact test}

\subsection{Skull fracture energy}

Skull fracture is a frequently observed type of severe head injury. Historically, different impact test set ups and techniques have been used for investigating skull fractures. The most fre quently used are drop tower and impactor pneumatic launcher [19]. Head protection measures and proposed skull fracture criteria typically include the absorbed energy until skull fracture [19 23]. The reference of skull fracture energy ranges from $14.0 \mathrm{~J}$ to $68.5 \mathrm{~J}$ [22]. More recent studies reported values of $21.1 \mathrm{~J} \leqslant E_{\text {sloul }}^{\text {frocure }} \leqslant 40.5 \mathrm{~J}$ at high impact velocities [23]. For compar ison, the impact velocity presented by a human head assuming a

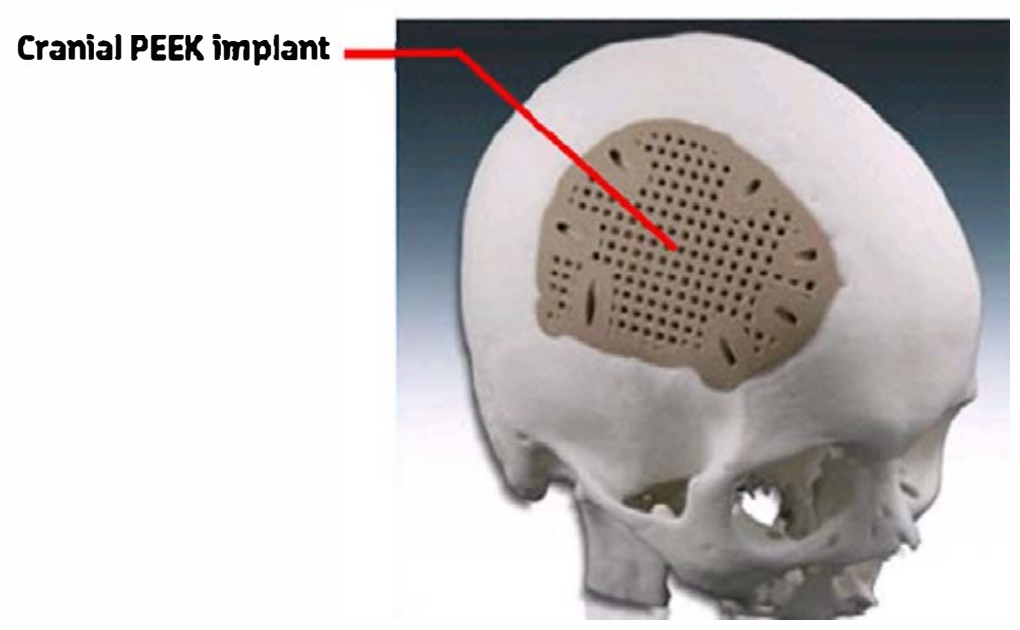

Fig. 1. Cranial implant using PEEK material [6]. 

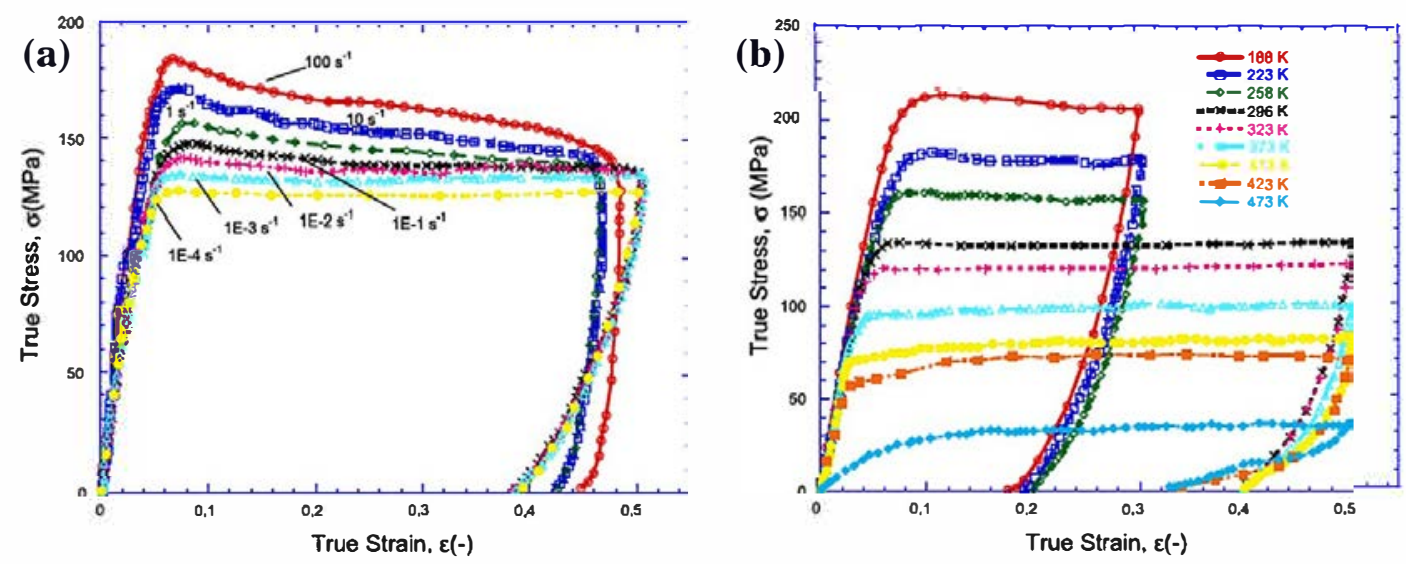

Fig. 2. Mechanical behavior of PEEK under compression for, (a) different initial stra in rates at room temperature and (b) different temperatures at $0.001 \mathrm{~s}{ }^{1}$ [11].

person with a height of $h \quad 1.8 \mathrm{~m}$, is equal to $V_{0} \quad \sqrt{ } 2 \mathrm{~g} h \approx 6 \mathrm{~m} / \mathrm{s}$. If we assumed an average mass of $\bar{m}_{\text {head }} \approx 4.5 \mathrm{~kg}$ for a human head, the maximum impact energy corresponding to an accidental fall is equal to $W_{\text {head }} \approx 80 \mathrm{~J}$. In this study, the kinetic energy range has been $21.0 \mathrm{~J} \leqslant E_{\mathrm{K}} \leqslant 131.0 \mathrm{~J}$ within the range of skull fracture energy and upper. For this proposal, perforation tests using rigid spheres have been conducted on plates of PEEK 450G and compared with Ti6Al4V titanium alloy.

\subsection{Setup}

The set up used was a gas gun capable of shooting a rigid spher ical projectile with a mass of $m_{p} 1.3 \mathrm{~g}$ and a diameter of $\phi_{p} \quad 7.25 \mathrm{~mm}$. This experimental device uses helium up to pres sures of 200 bar to impel the projectile. The initial impact velocity $V_{0}$ was in a range of $180 \mathrm{~m} / \mathrm{s} \leqslant V_{0} \leqslant 450 \mathrm{~m} / \mathrm{s}$. In order to measure the impact and the residual velocity, a high speed video camera, Photron Ultima APX RS, was used. Since the exposure time was very short, $10 \mu \mathrm{s}$, a $1200 \mathrm{~W}$ HMI lamp was used to ensure adequate lighting. The camera was configured to obtain $36,000 \mathrm{fps}$. Two materials, PEEK 450G and Ti6Al4V titanium alloy were studied. The thickness of each plate was selected to obtain comparable areal density [24], a parameter frequently used to optimize impact protection, Table 2 . The thickness of the Ti6Al4V was set at $t \quad 1 \mathrm{~mm}$ to provide a representative comparison. Due to the boundary conditions used to avoid sliding and to ensure correct clamping of the specimen, the size of the active part of the plate was reduced to $100 \times 100 \mathrm{~mm}^{2}$, Fig. 3 .

\section{Modeling behavior}

\subsection{Modeling behavior of PEEK}

\subsubsection{Viscoelasticity}

The stress strain curves obtained at different strain rate show the viscoelastic effect observed in unfilled PEEK [11], Fig. 2. This behavior is also reported by El Qoubaa and Othman [10]. For low strain rates, the difference between elastic modulus is weak and the value obtained is constant at $3600 \mathrm{MPa}$. For high strain rates,

Table 2

Biomaterials considered for impact testing.

\begin{tabular}{llll}
\hline Material & Dimensions $\left(\mathrm{mm}^{3}\right)$ & Mass $(\mathrm{gr})$ & Areal density $\left(\mathrm{kg} / \mathrm{m}^{2}\right)$ \\
\hline PEEK 450G & $130 \times 130 \times 3$ & 65.5 & 3.9 \\
Ti6Al4V & $130 \times 130 \times 1$ & 78.5 & 4.6 \\
\hline
\end{tabular}

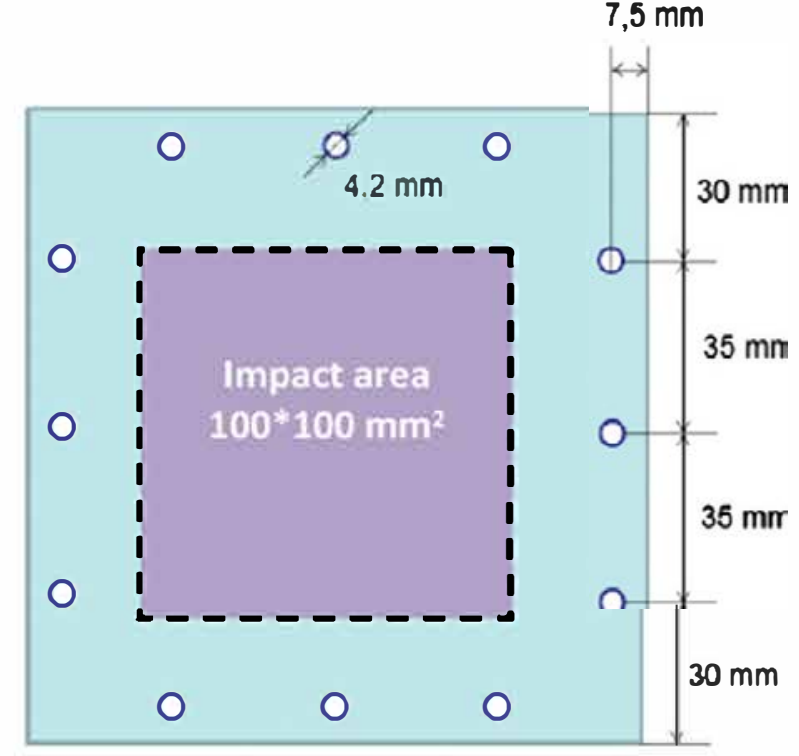

Fig. 3. Geometry of plate specimen and boundary conditions.

an increase is observed until a value of $3900 \mathrm{MPa}$ for $\dot{\bar{\varepsilon}} \approx 10^{2} \mathrm{~s}^{1}$ is observed according the Eq. (3), [26]:

E $\quad E_{0}+\eta \dot{\varepsilon}^{k}$

where $E_{0}$ is the quasi static elastic modulus, $\eta$ is the consistency parameter, and $k$ is the viscoelastic coefficient, Table 3. A direct identification of the material parameters which define the visco elastic behavior law with $E_{0}=3600 \mathrm{MPa}$ the static Young modulus for null strain rate.

\subsubsection{Viscoplasticity}

Different models have been developed with the aim of repro ducing the stress strain constitutive relationship of semi crystal line polymers based on two approaches [25,26]. Firstly, a phenomenological one based on the models previously developed for metal, to introduce the viscoplasticity behavior $[10,2528]$. Sec ondly, a physical one where the strain hardening of a semi crystal line polymer is due to entropic forces needed to orient the macromolecular chains $[29,30]$ or by considering the intermolecu lar and the molecular network resistances to deformation and stretching of the chains [31]. In this work, the phenomenological Johnson Cook (JC) model [32] was used as the material model, 
Table 3

Material parameters of the viscoelastic behavior law of PEEK 450G.

\begin{tabular}{lll}
\hline$E_{0}(\mathrm{MPa})$ & $\eta(\mathrm{MPa})$ & $k$ \\
\hline 3600 & 1.25 & 0.9 \\
\hline
\end{tabular}

according to strain rate and temperature sensitivity viscoplastic behavior of PEEK reported in [11], Fig. 2. Significant inelastic defor mation, denoted as viscoplastic, may be observed even at very small deformation levels, Fig. 2. For semicrystalline polymers, it is reported that the viscoplastic deformation of crystalline phase is analogous to the viscoplastic deformation of crystallographic materials [33]. The JC model is frequently used in ductile metal alloys [7] and it was previously used to analyze the dynamic behavior of polymer materials [25,34]. The JC model is generally pre implemented in finite element (FE) codes, including ABAQUS/ explicit [35]. This hardening law is defined by Eq. (2). The first term defines strain hardening $\bar{\varepsilon}^{p}$, the second strain rate sensitivity $\dot{\bar{\varepsilon}}^{p}$ and the third one is related to thermal softening $\Theta$, Eqs. (3) and (4)

$\sigma\left(\varepsilon^{p}, \dot{\varepsilon}^{p}, T\right) \quad\left[A+B \cdot\left(\varepsilon^{p}\right)^{n}\right]\left[1+C \cdot \ln \left(\frac{\dot{\varepsilon}^{p}}{\dot{\varepsilon}_{0}^{p}}\right)\right]\left[\begin{array}{ll}1 & \Theta^{m}\end{array}\right]$

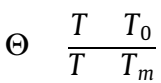

where $A$ and $B$ are material constants, $n$ is the strain hardening exponent, $C$ the strain rate sensitivity parameter, $m$ is the temper ature sensitivity, $T_{0}$ is the initial temperature and $T_{m}$ is the melting temperature. In addition, this constitutive relation coupled to the heat equation, Eq. (5), allows us to obtain the temperature increase $\Delta T$, in adiabatic conditions:

$\Delta T\left(\varepsilon^{p}, \dot{\varepsilon}^{p}, T_{0}\right) \quad \frac{\beta}{\rho \cdot C_{p}} \int_{\varepsilon}^{\varepsilon^{p}} \sigma\left(\varepsilon^{p}, \dot{\varepsilon}^{p}, T\right) d \varepsilon^{p}$

where $T$ is the current temperature, $T_{0}$ is the room temperature, and $\beta$ is the Quinney Taylor heat fraction coefficient, $\rho$ is the density of material and $C_{p}$ is the specific heat at constant pressure. The model parameters were identified according to the experimental results of compressive tests at various strain rates and temperatures [11], Fig. 2, with the methodology reported for ductile metals $[7,36]$ and polymer [34]. First, the hardening parameters $A, B$ and $n$ of the JC model were identified on the basis of tests at room temper ature. Parameter $C$ was obtained by Eq. (6) at different strain rates

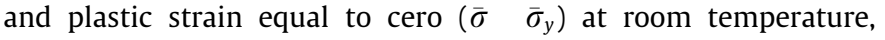
$296 \mathrm{~K}$. The temperature sensitivity parameter $m$ was identified by Eq. (7) during compressive tests over with a range of imposed tem peratures, Fig. 2, from initial temperature to transition temperature.

$$
\begin{gathered}
C \frac{\sigma_{y} A}{A \cdot \ln \left(\frac{\dot{\underline{g}} p}{\varepsilon_{0}^{p}}\right)} \\
\left.m \frac{1 \frac{\sigma}{\left(A+B \cdot\left(\varepsilon^{p}\right)^{n}\right)}}{\ln \left(\frac{T T_{0}}{T} T_{m}\right.}\right)
\end{gathered}
$$

Different authors have measured the Quinney Taylor coefficient in polymers [37 39]. In this work, it is assumed constant and equal to ratio $\beta=0.9$. This coefficient value has been reported for the inelas tic work fraction generating the heat of semicrystalline polymers [40]. The identified values of JC model parameters are indicated in Table 3. Fig. 4 shows the comparison between experimental data [11] and JC model data for different strain rates at room tempera ture. Adequate predictions are obtained with the identified con stants, Table 4 . The strain rate and the temperature sensitivity of the 450G PEEK material are reported in Fig. 5, [10,11]. As ductile metals, PEEK 450G shows non linear strain rate sensitivity and the stress increase is more significant at high strain rates than low strain rates [10]. Although this non linear strain rate of the material cannot be completely defined using the JC model due to the analytical formulation (Eq. (3)), good agreement is obtained for the identified constants from quasi static to dynamic loading. In the range of strain rates from $10{ }^{4} \mathrm{~s}^{1}$ to $10 \mathrm{~s}^{1}$, the differences between experimental data and JC model are less than $10 \%$. For high strain rates, from $10 \mathrm{~s}^{1}$ to $10^{4} \mathrm{~s}^{1}$, the differences between experi mental data and JC model are less $7 \%$.

\subsubsection{Fracture model}

To define completely the problem of plate impact perforation of PEEK it is necessary to introduce a fracture model. Some results have been reported in the literature concerning failure strain of unfilled PEEK $[11,15]$ and other semicrystalline polymers such as UHMWPE [39]. In these studies, ductility of semicrystalline poly mers, associated with void coalescence due tensile states, have been reported as dependent on the initial stress triaxiality $\sigma^{*}\left(\sigma^{*} \quad \sigma_{m} / \bar{\sigma}\right.$, where $\sigma_{m}$ is the mean stress and $\bar{\sigma}$ is the equivalent stress) and strain rate $\dot{\bar{\varepsilon}}^{p}$. For PEEK 450G, Sobieraj et al. [9] reported an average value of failure strain of 1.1 for unnotched specimen and stress triaxiality of 0.33 . However, for high triaxiality values, these authors [9] found that there was a dramatic change in the fracture micromechanism of PEEK, and the deformation and frac ture micromechanics changed drastically, from one of plastic deformation and void coalescence to one dominated by crazing and brittle fast fracture with a average value of failure strain of 0.05 for notched specimens. Mourad et al. [41] reported that the ductility of semicrystalline polymer UHMWPE is strongly depen dent on strain rate in such a way that fracture strain reduces with strain rate. For PEEK 450G, Rae et al. [11] found that strain failure was dependent on strain rate and temperature, with a clear upward trend in strain to failure when the temperature was increased. The fracture model used in this work has been proposed by Johnson and Cook [42] to include strain hardening $\bar{\varepsilon}^{p}$, strain rate $\dot{\bar{\varepsilon}}^{p}$ and temperature $T$ dependencies. This model includes stress tri axiality $\sigma^{*}$, an important parameter for PEEK material. The JC frac

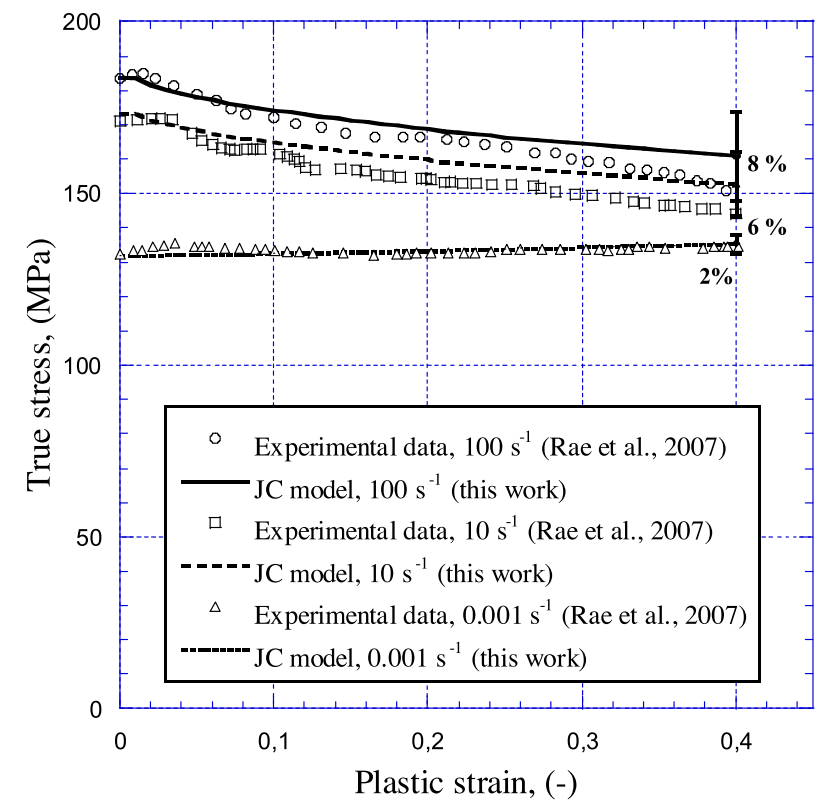

Fig. 4. Comparison of stress-strain of PEEK $450 \mathrm{G}$ given by the experimental data [11] and JC model predictions at room temperature and different strain rates. 
Table 4

Constants used to define the thermoviscoplastic behavior of PEEK $450 \mathrm{G}$ at high strain rates in adiabatic conditions.

\begin{tabular}{|c|c|c|c|c|c|c|c|}
\hline \multicolumn{2}{|l|}{ Elasticity } & \multicolumn{6}{|c|}{ Themnoviscoplastic behavior } \\
\hline$E_{0}(G P a)$ & $v(-)$ & $A(\mathrm{MPa})$ & $B(\mathrm{MPa})$ & $n(-)$ & $\varepsilon_{0}^{p}\left(s^{1}\right)$ & $C(-)$ & $m(-)$ \\
\hline 3.6 & 0.4 & 132 & 10 & 1.2 & 0.001 & 0.034 & 0.7 \\
\hline $\begin{array}{l}\text { Other phys } \\
\rho\left(\mathrm{kg} / \mathrm{m}^{3}\right)\end{array}$ & \multicolumn{6}{|c|}{ Other physical constants } & \\
\hline 1304 & & 0.9 & & 2180 & & 614 & \\
\hline
\end{tabular}
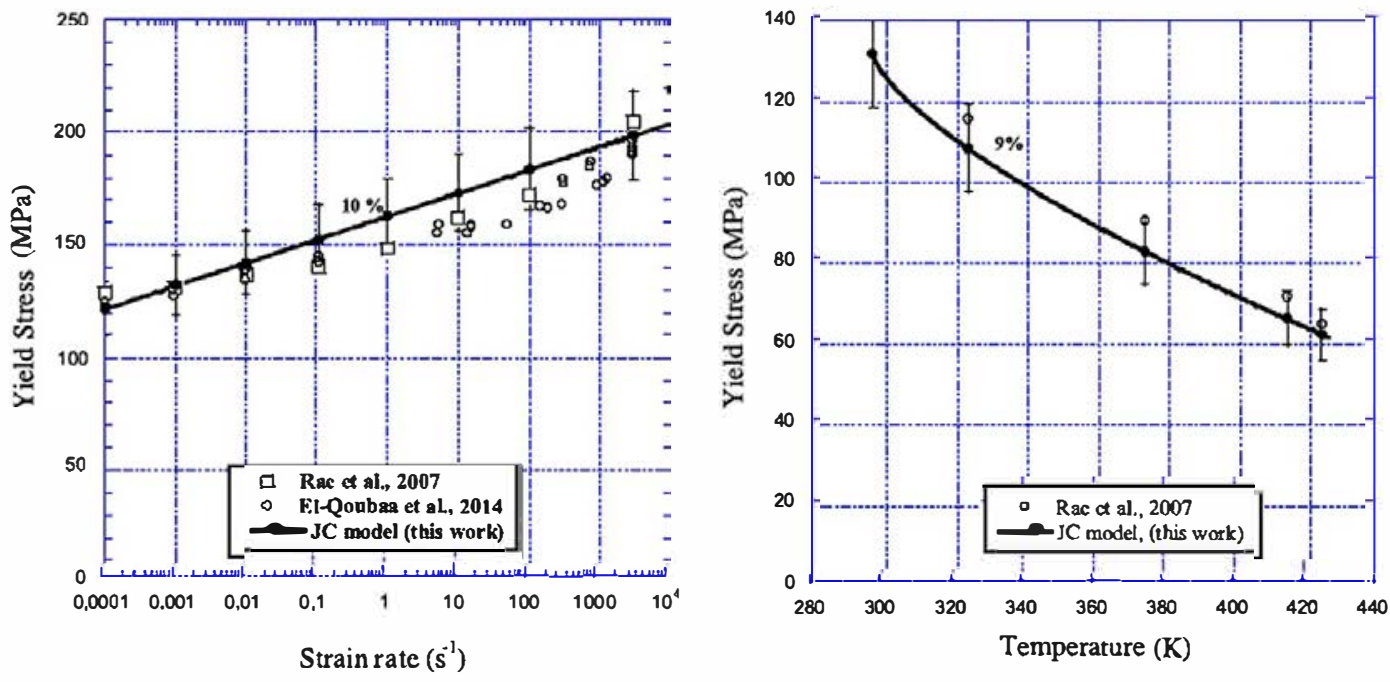

Fig. 5. Strain rate (a) and the temperature sensitivity (b) of PEEK 450G, experimental data [10,11] a nd JC model predictions.

ture model is frequently used in studies of ductile metal alloys [7] and it was previously used to analyze the fracture behavior of semicrystalline polymer [41]. Failure is assumed when a parameter $D$ exceeds unity. The $D$ para meter is summed over all increments of deformation. The evolution of $D$ is the following:

$D\left(\varepsilon^{p}, \dot{\varepsilon}^{p}, T\right) \quad \sum \frac{\Delta \varepsilon^{p}}{\varepsilon_{f}^{p}\left(\dot{\varepsilon}^{p}, T, \sigma^{*}\right)}$

where $\Delta \bar{\varepsilon}^{p}$ is an increment of accumulated equivalent plastic strain that occurs during an integration cycle, and $\bar{\varepsilon}_{f}^{p}$ is the critical failure strain level. This kind of fracture model is erosive in ABAQUS induc ing an instantaneous element deletion [7] when an imposed plastic strain level is reached. Thus, using this kind of criterion the mesh in the damaged part must be very fine to not affect the numerical results in terms of energy. The plastic failure strain $\bar{\varepsilon}_{f}^{p}$ is assumed to be dependent on a non dimensional plastic strain rate $\dot{\varepsilon}^{p} / \hat{\varepsilon}_{0}$, a dimensionless pressure deviatoric stress ratio $\sigma^{*}$ and a non dimen sional temperature $\Theta$ as defined previously. The dependencies are assumed separable and take the following expression:

$\varepsilon_{f}^{p} \quad\left[D_{1}+D_{2} \cdot \exp \left(D_{3} \cdot \sigma^{*}\right)\right]\left[1+D_{4} \cdot \ln \left(\frac{\dot{\varepsilon}^{p}}{\dot{\varepsilon}_{0}^{p}}\right)\right]\left[1+D_{5} \cdot \Theta\right]$

where $D_{i}$ are failure constants. The constant $D_{1}$ implies a finite strain to fracture even at very high values of stress triaxiality [41]. This value is assumed to be $D_{1} \quad 0.05$, according an average failure strain of 0.05 for high triaxiality reported for PEEK 450G [9]. The constant $D_{2}$ and $D_{3}$ are identified from experimental data [9] often sile tests of unnotched specimens of PEEK $450 \mathrm{G}$ at strain rate equal to $0.001 \mathrm{~s}^{1}$ and room temperature. The value is close to $\tilde{\varepsilon}_{j}^{p} \rightarrow 1.1$ in these conditions. The constant $D_{4}$ and $D_{5}$ are identified from exper imental data [11] of uniaxial tests of unnotched specimens of PEEK
$450 \mathrm{G}$ at different strain rate and temperatures. According these experimental data $D_{4}$ defines the dependence on the strain rate as negative sensibility whereas $D_{5}$ defines the temperature as large positive sensibility, Fig. 6 . The constants identified of fracture model of PEEK 450G are given in Table 5.

\subsection{Modeling behavior of Titanium Ti6Al4V}

Ti6Al4V titanium alloy is a biocompatible material with high yield stress, $\sigma_{y}=1098 \mathrm{MPa}$ and has been frequently used for med ical applications [1]. This material has been widely studied with reports of the plasticity and damage models available in the liter ature [43 45], including strain rate and temperature dependence. To define its thermoviscoplastic behavior several approaches may be used including physical [43] and phenomenological formula tions [44,45]. In this work, Johnson Cook hardening law [32], Eq. (3) and JC fracture model [42]. Eq. (9), have been used to describe the titanium alloy behavior drawing on reported data [45], Tables 6 and 7.

\section{Numerical model}

A Lagrangian 3D finite element model for the simulation of the perforation process was developed in ABAQUS/explicit [35]. The geometry of plates is equal to the active area of the experimental tests specimens $(100 \times 100 \mathrm{~mm})$ with a value of thickness of $1 \mathrm{~mm}$ for Ti6Al4V and $3 \mathrm{~mm}$ for PEEK (Table 2). The fully 3D con figuration allows the model to describe the radial cracking and the petalling failure mode that characterize the perforation of plates by spherical projectiles [46]. The target mesh developed is shown in Fig. 7, where twelve elements were placed across the thickness of the target. This is in agreement with the recommendations 

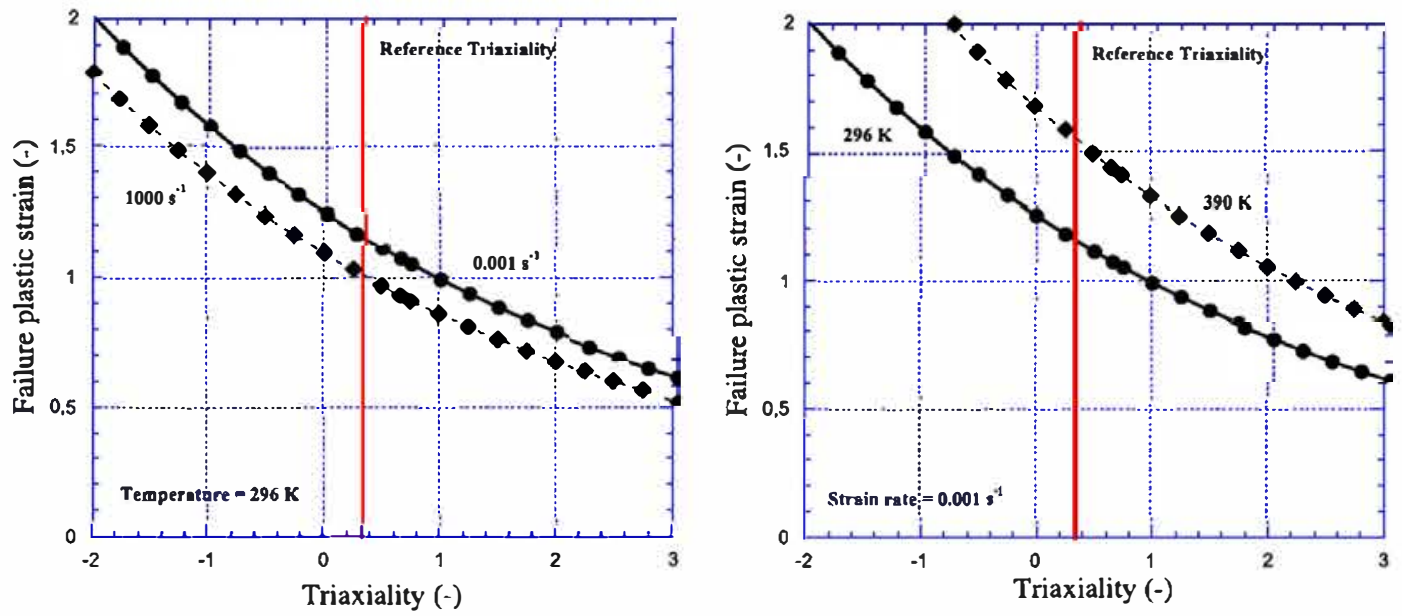

Fig. 6. Failure strain level (JC fracture model) depending on solicitation state at different strain rates (a) and at different temperatures (b).

Table 5

Constants used to define fracture model of PEEK 450G.

\begin{tabular}{lllll}
\hline \multicolumn{4}{l}{ Fracture criterion constants } \\
\hline$D_{1}$ & $D_{2}$ & $D_{3}$ & $D_{4}$ & $D_{5}$ \\
\hline 0.05 & 1.2 & -0.254 & -0.009 & 1.0 \\
\hline
\end{tabular}

reported [35], where it is suggested that at least four elements should be used through the thickness when modeling any struc tures carrying bending loads. The mesh presents radial symmetry to avoid appearance of spurious generation of cracks. The mesh is split into three different zones. The zone directly affected by the impact has been meshed with 32,400 tri linear elements with reduced integration (C3D8R in ABAQUS notation). In order to reduce the computational time, beyond the zone directly affected by the impact is defined a transition zone using 48,000 elements. After the transition zone, the mesh is defined using C3D8R ele ments until reaching the perimeter of the target. This optimum configuration has been obtained from a convergence study using different mesh densities. Since the experimental observations revealed absence of erosion on the projectile surface after the impact (the projectile was not deformed plastically in any test), the projectile has been defined as rigid body. This enables a reduc tion in the computational time required for the simulations. A con stant friction coefficient value $\mu=0.2$ has been used to define the contact projectile/plate [47]. The potential dependence of the fric tion coefficient on the temperature and the sliding velocity is not taken into account. The constant value used for the friction coeffi cient is based on the assumption of a constant pressure along the projectile plate contact zone. The authors confimed this hypothe sis by $\mathrm{FE}$ analysis of different projectile target configurations [45].
Table 7

Constants used to define fracture model [44].

\begin{tabular}{lllll}
\hline \multicolumn{4}{l}{ Fracture criterion constants } \\
\hline$D_{1}$ & $D_{2}$ & $D_{3}$ & $D_{4}$ & $D_{5}$ \\
\hline-0.09 & 0.27 & 0.48 & 0.014 & 3.87 \\
\hline
\end{tabular}

The impact velocities covered with the numerical simulations are those covered during the normal impact experiments.

\section{Results and discussion}

\subsection{Energy absorption and residual velocity}

Firstly, the experimental results of impact velocities are ana lyzed. Fig. 8a shows the residual velocity versus impact velocity $\left(\begin{array}{ll}V_{r} & V_{0}\end{array}\right)$ curves obtained for both materials tested, PEEK $450 \mathrm{G}$ and Ti6Al4V. The ballistic limit $V_{\Delta}$ is the maximum value of the ini tial impact velocity $V_{0}$ which induces a residual velocity $V_{r}$ equal to zero. The ballistic limit of PEEK $450 G, V_{b l}^{\text {PEEK }} \approx 265 \mathrm{~m} / \mathrm{s}$ was found greater than that corresponding to the Ti6Al4V plates, $V_{b l}^{\mathrm{T} i 6 \mathrm{Al} 4 \mathrm{~V}} \approx 232 \mathrm{~m} / \mathrm{s}$. The results shown in Fig. 8 have fitted via the expression proposed by Recht and Ipson [48]:

$V_{r} \quad\left(\begin{array}{ll}V_{0}^{k} & V_{b}^{k}\end{array}\right)^{1 / A}$

where $k$ is a fitting parameter. The values of $k$ determined are $k=1.9$ for PEEK $450 G$ and $k=2$ for Ti6Al4V. The residual velocity of PEEK $450 \mathrm{C}$ plates within the range of impact velocities tested is lower than Ti6Al4V. It was noted that the flow stress of Ti6Al4V is ten times higher than the flow stress of PEEK $450 \mathrm{G}$ in quasistatic conditions [11,45], and seven times in dynamic conditions,

Table 6

Constants used to define the thermoviscoplastic behavior of Ti6Al4V at high strain rates in adiabatic conditions [45].

\begin{tabular}{|c|c|c|c|c|c|c|c|}
\hline \multicolumn{2}{|l|}{ Elasticity } & \multicolumn{6}{|c|}{ Thermoviscoplastic behavior } \\
\hline$E(\mathrm{GPa})$ & $v(-)$ & $A(\mathrm{MPa})$ & $B(\mathrm{MPa})$ & $n(-)$ & $\mathscr{D}_{0}^{P}\left(s^{\prime}\right)$ & $C(-)$ & $m(-)$ \\
\hline 109.8 & 0.31 & 1098 & 1092 & 0.93 & 1.0 & 0.014 & 1.1 \\
\hline \multicolumn{2}{|c|}{$\begin{array}{l}\text { Other physical constants } \\
\rho\left(\mathrm{kg} / \mathrm{m}^{3}\right)\end{array}$} & \multicolumn{2}{|l|}{$\beta(-)$} & \multicolumn{2}{|c|}{$C_{p}(\mathrm{~J} / \mathrm{kg} \mathrm{K})$} & \multicolumn{2}{|l|}{$r_{m}(\mathrm{~K})$} \\
\hline 4428 & & 0.9 & & 560 & & 1878 & \\
\hline
\end{tabular}



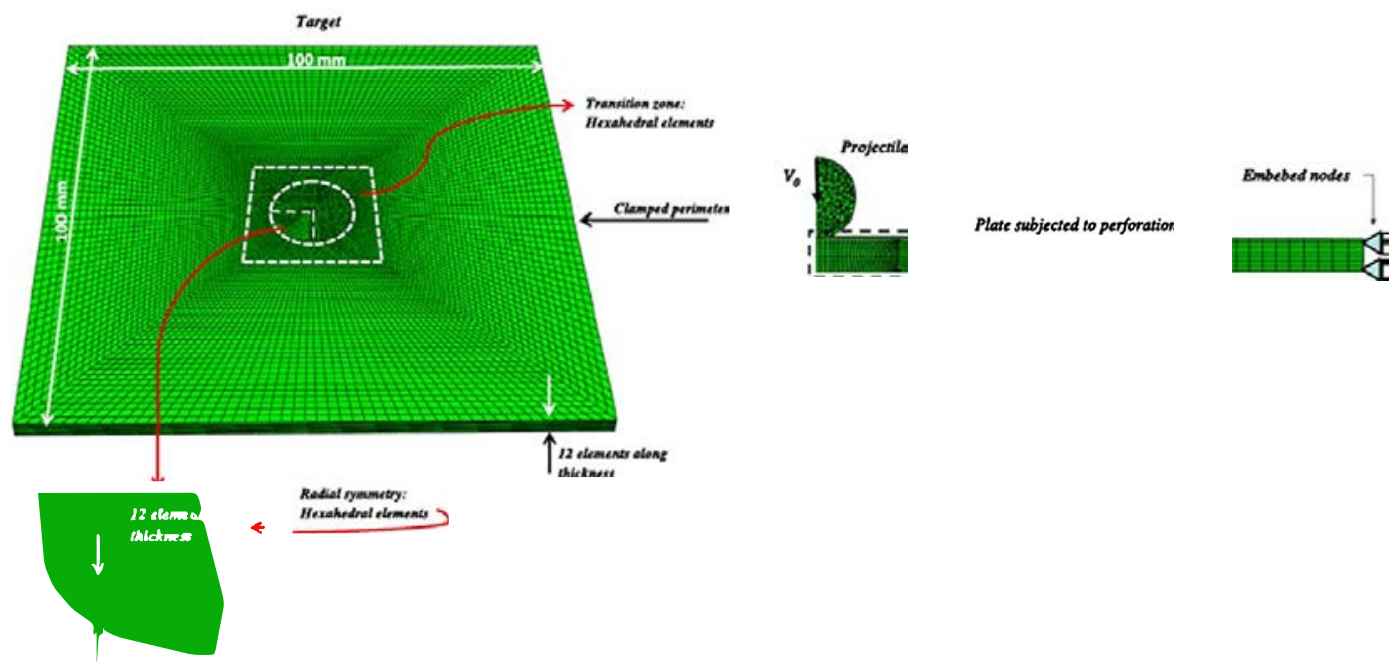

Fig. 7. Numerical configuration used in the simulations.

$10^{3} s^{1} 10^{4} s^{1},[10,11]$. This suggests that the energy absorption mechanics shown by both materials investigated are largely differ ent to each other. Thanks to the measurements described previ ously, it is possible to estimate the energy absorption $W$ of PEEK $450 \mathrm{G}$ material under dynamic impact by Eq. (11) and the minimum energy to perforation, $W_{\text {perforation, }}$ Eq. (12)

W $\frac{1}{2} m_{p}\left(V_{\mathrm{a}}^{2}\right.$

$W_{\text {perforation }}$

Fig. $8 \mathrm{~b}$ shows the kinetic energy of the projectile converted into energy absorption $W$ of plate. For both materials $W$ increases with initial velocity. This tendency is in agreement with experimental results published in the literature for spherical noses of projectile [7]. Comparing the values obtained, it is observed that PEEK mate rial can absorb enough energy to avoid skull injury independent of the impact velocity, Fig. $8 \mathrm{~b}$. The reference used for comparison is the maximum skull fracture energy, $E_{\text {skull }}^{\text {frocare }} 40.5 \mathrm{~J}$, reported in [23]. The values of perforation energy are respectively $W_{\text {perforation }}^{\text {PEEX }} 45.6 \mathrm{~J}$ and $W_{\text {perforation }}^{\text {TiGALV }} 35 \mathrm{~J}$. Moreover, in the full range of impact velocities, PEEK material is more efficient for energy absorption compared to titanium alloy with a medium ratio of
$R$ 1.26. One of the reasons for the good capability to absorb energy is the adiabatic deformation of PEEK at high strain rates with large strain values $(\varepsilon>1.0)$. This behavior is characteristic of com pressive states in dynamic process, as reported Rae et al. [11] for Taylor impact tests.

\subsection{Failure mode}

\subsubsection{Ductile behavior of PEEK}

Figs. 9 and 10 illustrate the final stage of the impact process for different initial velocities and both materials tested. The failure mode of PEEK plates is clearly different from that observed in tita nium alloy. The shear failure of Ti6Al4V plates is characterized by small energy consumption. Namely, the energy required for perfo ration is that required for the onset of the shear band, plug ejection and cracks propagation, Fig. 10. The length of cracks is larger at velocities below the ballistic limit, and the crack propagation path is transverse to the rolling direction [49]. Fig. 10. Once the instabil ity is formed, a very low energy consumption is needed to perfo rate the plate. However, at all impact energies, ductile process of PEEK plates was noted and no evidence of brittle failure was observed, Figs. 9 and 11. Moreover, multi hit capability [50] for impact absorption energy of PEEK material has been demonstrated due to localized ductile damage, Fig. 11b. Based on the ballistic
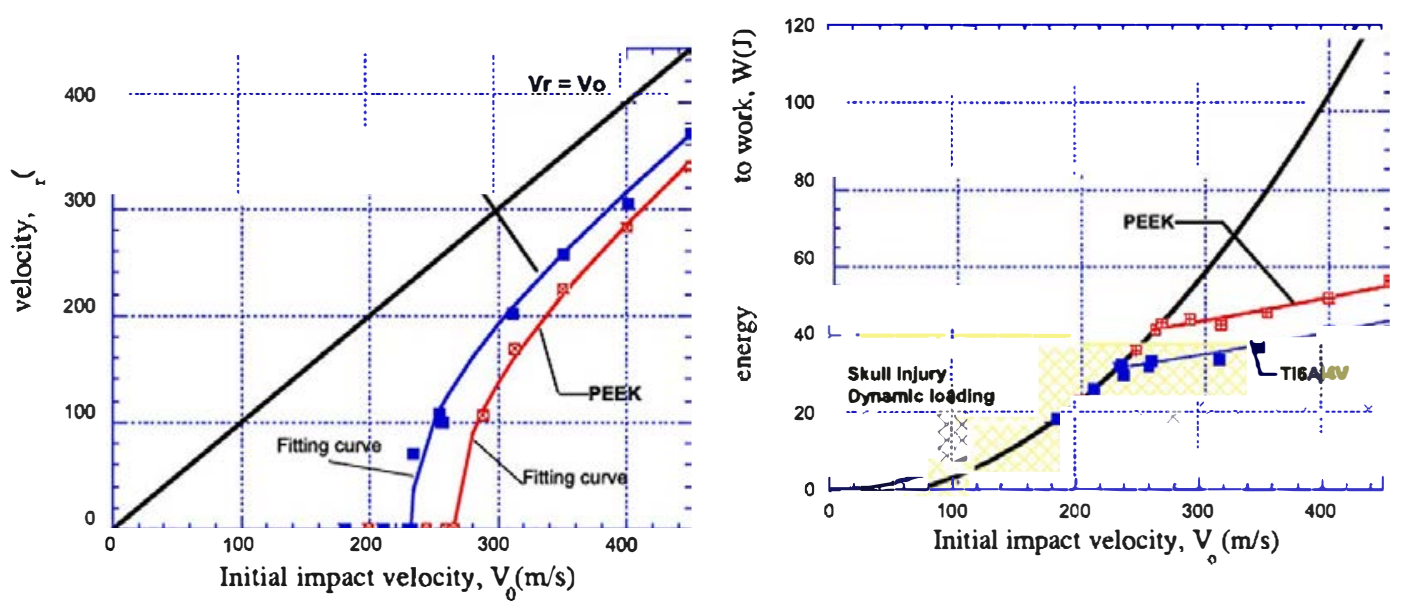

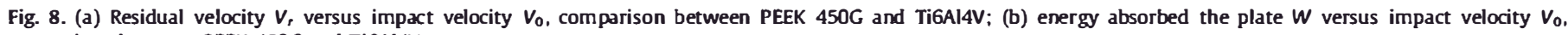
comparison between PEEK 450G and Ti6Al4V. 

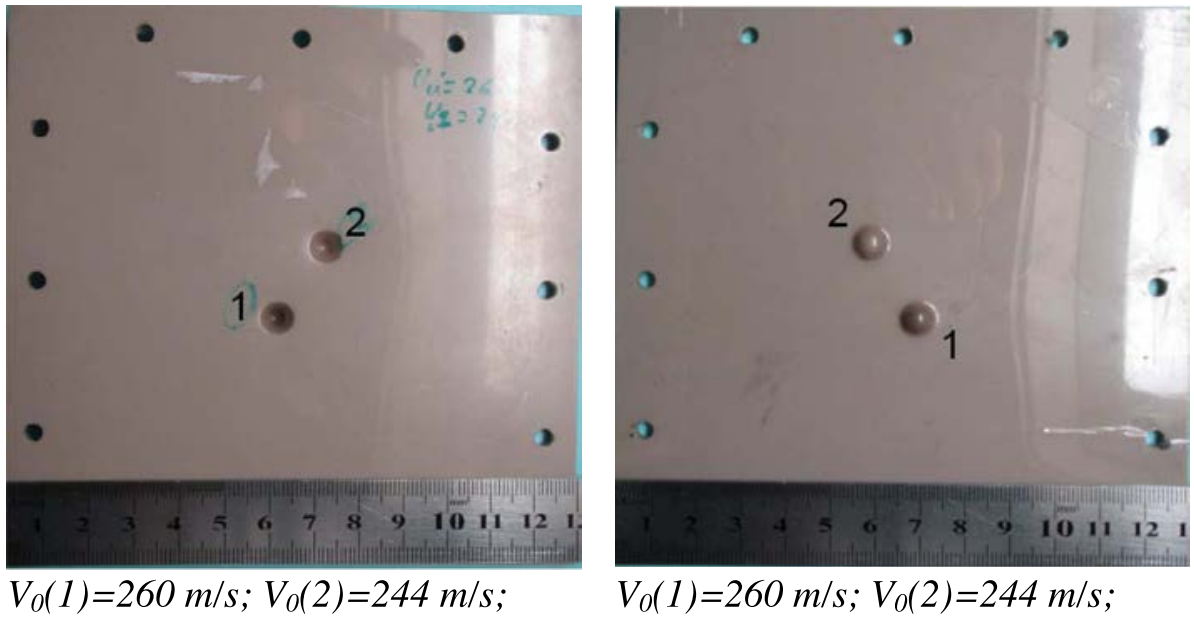

$V_{o}(1)=260 \mathrm{~m} / \mathrm{s} ; V_{o}(2)=244 \mathrm{~m} / \mathrm{s}$;
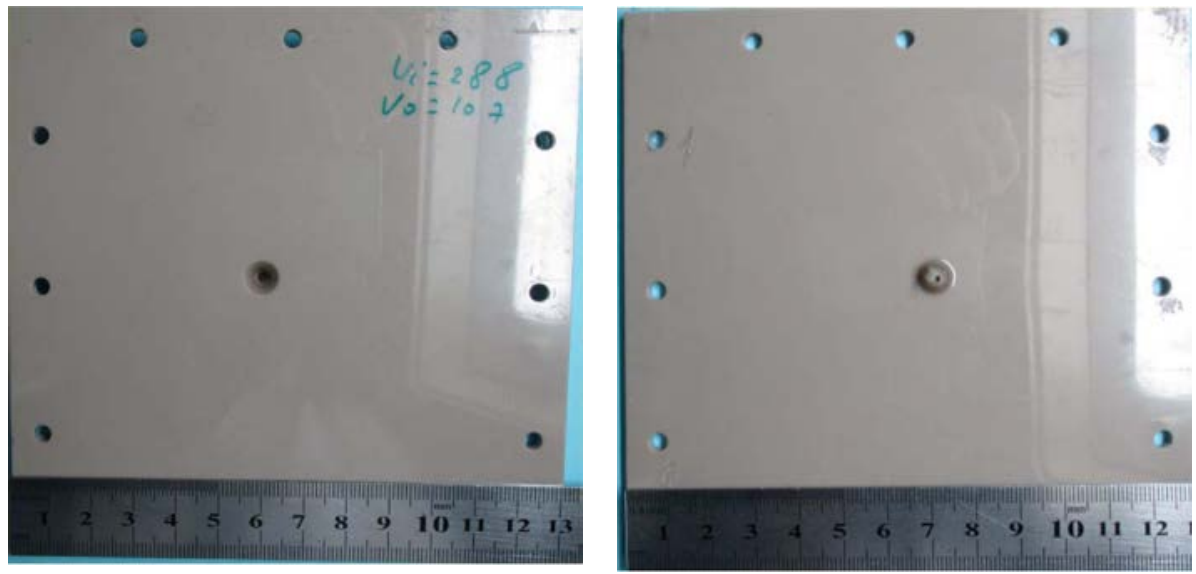

$V_{0}=288 \mathrm{~m} / \mathrm{s} ; V_{r}=107$; front

$V_{0}=288 \mathrm{~m} / \mathrm{s} ; V_{r}=107 ;$ back

Fig. 9. Final stage of the perforation process of PEEK for different impact velocities (front and back of plates).

tests, it is observed a ductile failure mode without plug ejection as frequently observed for metal materials using a spherical or hemi spherical projectile $[7,46]$.

Comparing PEEK with metals, a hole enlargement is observed when the projectile is passing through the plate followed by an enclosing hole stage, Fig. 12. A local deflection is also observed without real bending of the whole plate compared to metal. The plastic deformation is confined close to the impact zone, with a maximum value of two times the diameter of the projectile. More over, using SEM photo, it is possible to note a ductile failure mode and large plastic deformation lines, Fig. 13. The same failure mode has been observed independent of the initial impact velocity $V_{0}$ used. This observation agrees with the results provided by Rae et al. using Taylor's test at high impact velocity [11].

\subsubsection{Darkening at large strain}

At all velocities, darkening is noticed in the highly deformed regions associated to local damage in plates. Fig. 14 clearly shows the concave rod end and the discolouration associated with the large strain regions. A number of authors have focused on identify ing whether the colour change of PEEK was a result of the strain rate or large strain. Fig. 14 shows the cross sections of virgin and three large strain samples impacted at different velocities below ballistic limit and photographed under identical conditions. The more impact energy, the larger the strain and darker the damage area. From the associated colour changes it is therefore clear that the colour change is associated with large strain compression, not strain rate. PEEK in tension undergoes stress whitening in com mon with many other polymers.

\subsubsection{Crystallinity at high strain rate and large strain}

The percentage of crystallinity is responsible for the material fragility. To change the microstructure from amorphous to crystal line, the material needs additional energy mainly derived from temperature increase $\Delta T$. For this reason, it is interesting to ana lyze the behavior of PEEK polymer at high velocity impact $V_{0}$ to check if a brittle transition is observed since for high velocity, the initial temperature $T_{0}$ shows a strong increase. Differential scan ning calorimetry (DSC) experiments were carried out in a Perkin Elmer Diamond calorimeter with nitrogen as the purge gas. PEEK samples of highly deformed regions corresponding to different impact energies of tests have been analyzed. Samples with a mass of $\approx 10 \mathrm{mg}$ were sealed in a $50 \mathrm{ml}$ aluminium pan, and an empty pan was used as reference. They were heated from $293 \mathrm{~K}$ to $433 \mathrm{~K}$ at a heating rate of $10 \mathrm{~K} / \mathrm{min}$ and then cooled at the same rate. Enthalpies of melting were determined with a average value of $\Delta H_{f} \approx 39 \mathrm{Jg}{ }^{1}$. The crystallinity of all samples deformed to large strains was found similar and equal to $30 \%$. There is a point of con tention in this regard about the relationship between high strain rate, large strain and crystallinity. While some authors, Hamdan and Swallowe [12] reported an increase in crystallinity in dynamic conditions under high strain rates, $\dot{\varepsilon} \approx 10^{3} \mathrm{~s}{ }^{1}$, others authors reported decrease of crystallinity in dynamic conditions for sam ples deformed to large strains $\varepsilon>0.1$ [11]. An explanation of this 


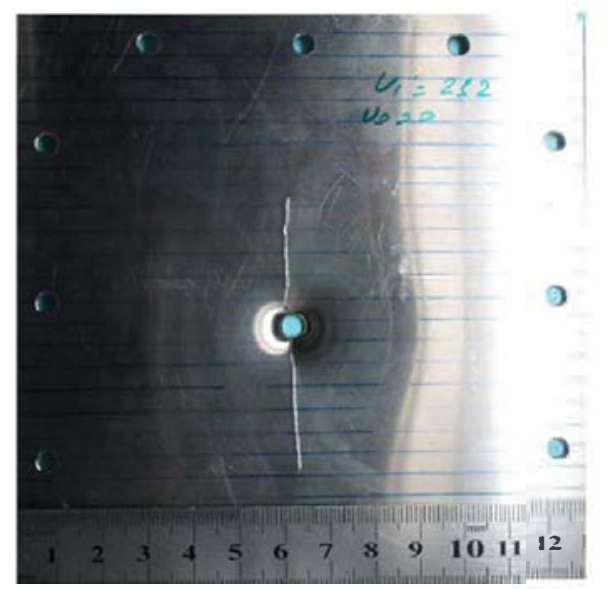

$V_{0}=232 \mathrm{~m} / \mathrm{s} ; V_{r}=0$; front

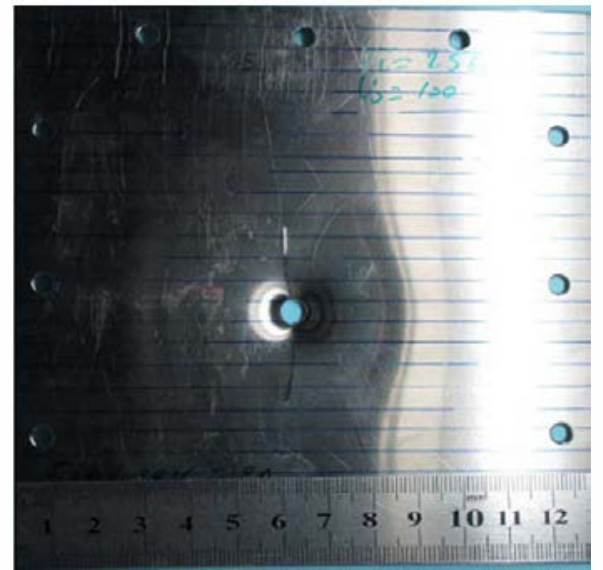

$V_{0}=256 \mathrm{~m} / \mathrm{s} ; V_{r}=100 ;$ front

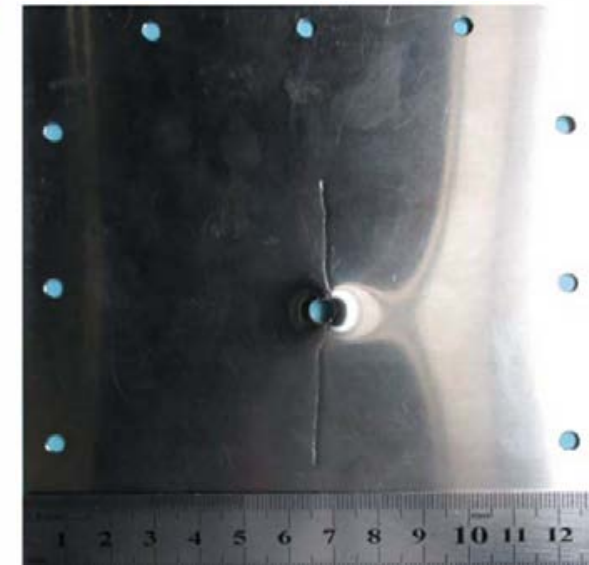

$V_{0}=232 \mathrm{~m} / \mathrm{s} ; V_{r}=0 ;$ back

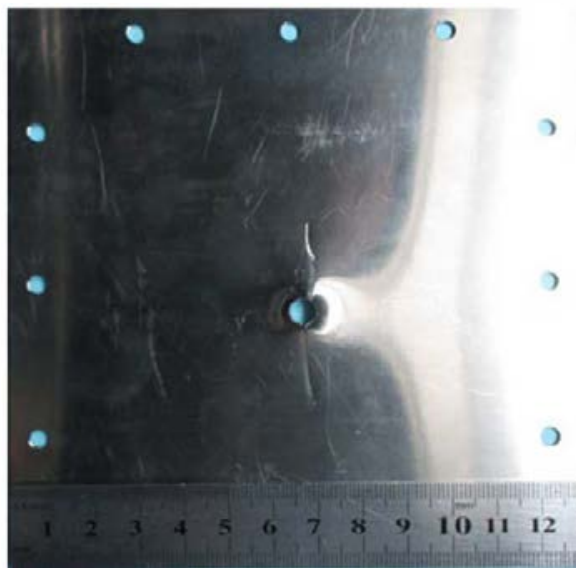

$V_{0}=256 \mathrm{~m} / \mathrm{s} ; V_{r}=100 ;$ back

Fig. 10. Final stage of the perforation process of Ti6Al4V for different impact velocities (firont and back of plates).

(a)

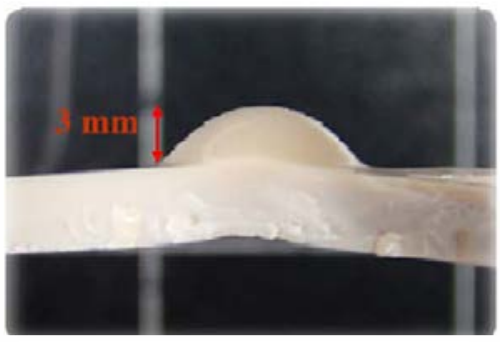

(b)

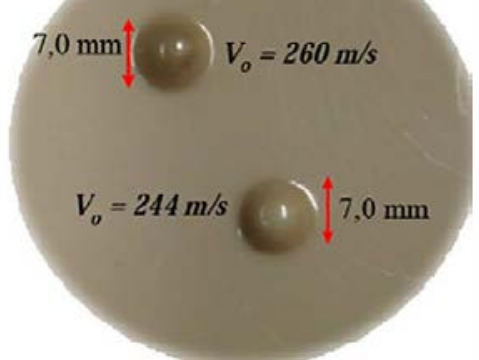

Fig. 11. Final stage of the impact process of PEEK at impact velocity below ballistic limit: (a) $V_{0}=200 \mathrm{~m} / \mathrm{s}$; (b) two different impact at $V_{0}=260 \mathrm{~m} / \mathrm{s}$ and $V_{0}=244 \mathrm{~m} / \mathrm{s}$.
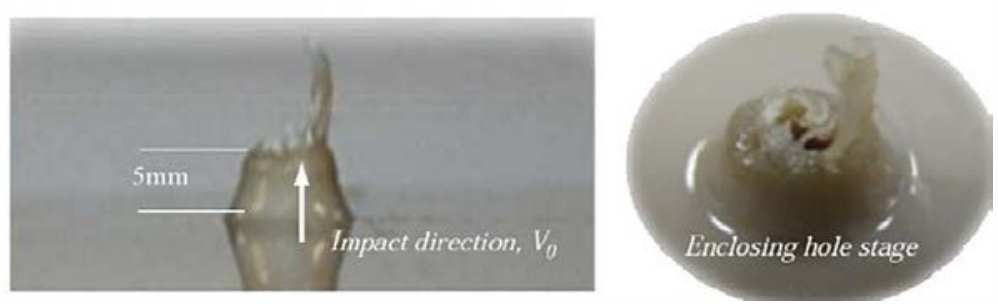

Fig. 12. Final stage of PEEK at impact velocity above ballistic limit: $V_{0}=288 \mathrm{~m} / \mathrm{s}\left(V_{r}=107 \mathrm{~m} / \mathrm{s}\right)$. 


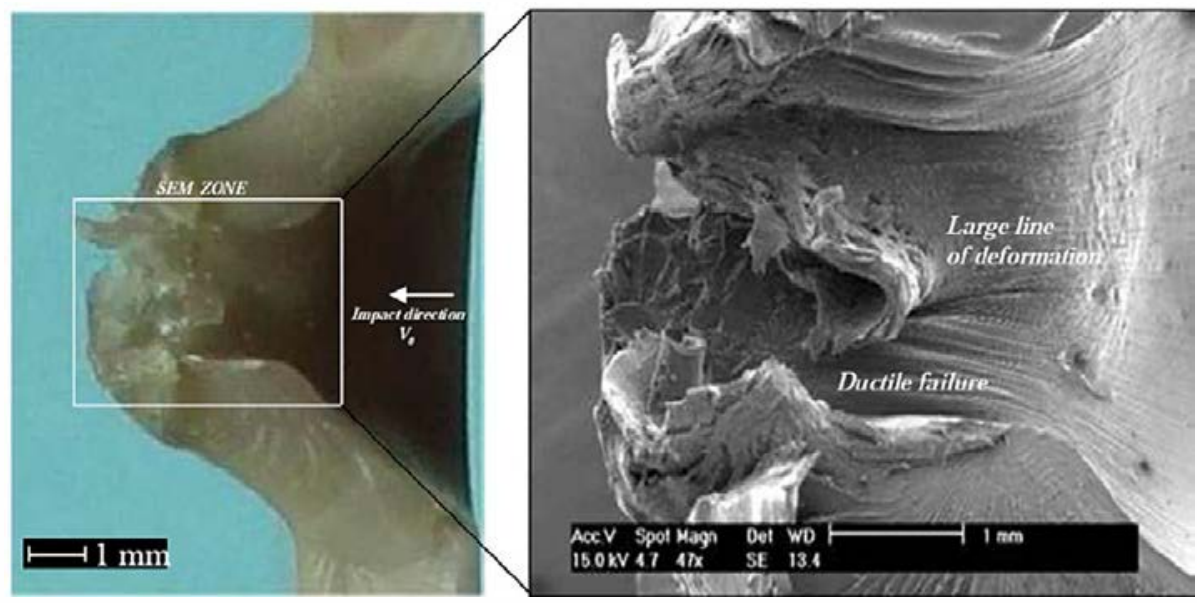

Fig. 13. Cross section of final stage of PEEK at impact velocity $V_{0}=288 \mathrm{~m} / \mathrm{s}\left(V_{r}=107 \mathrm{~m} / \mathrm{s}\right)$.
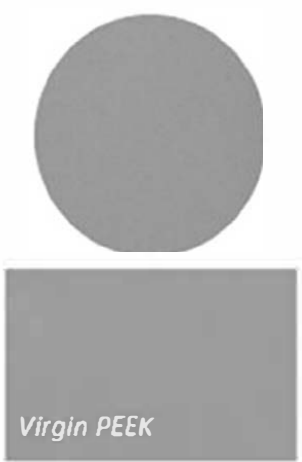
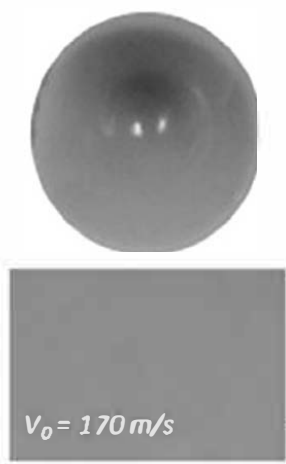
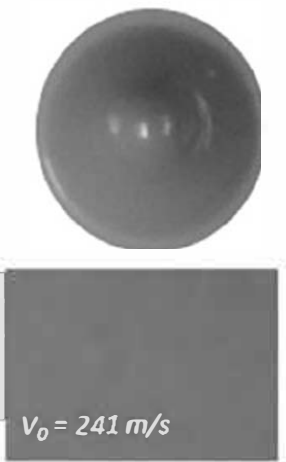
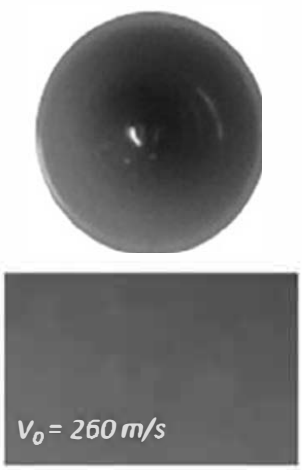

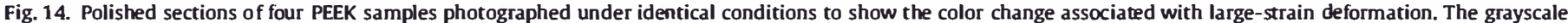
value, in the range from 0 to 255 where 255 is black, 93 is for virgin PEEK, 114 for $V_{0}=170 \mathrm{~m} / \mathrm{s}, 141$ for $V_{0}=241 \mathrm{~m} / \mathrm{s}$ and 156 for $V_{0}=260 \mathrm{~m} / \mathrm{s}$.
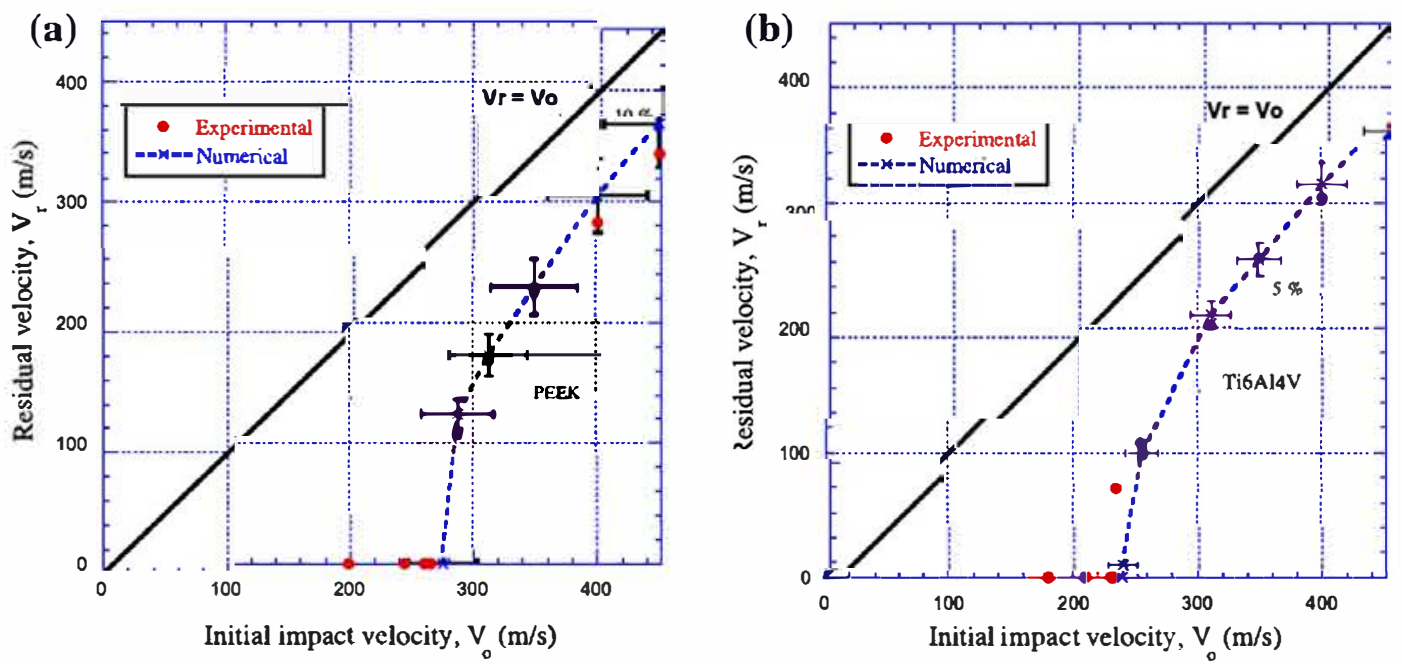

Fig. 15. Experimental and numerical data of residual velocity versus impact velocity: (a) PEEK 450G, (b) Ti6Al4V.

behavior is not obvious. In the research reported here, no changes in degree of crystallinity in relation with virgin PEEK were mea sured. Below glass transition temperature, crystallinity evolution can be considered as a competition between the stabilizing effect of strain rate on crystal structure [51] and the probable destruction associated with large strain. In this regards, it has been reported that high compressive deformation can degrade the crystalline structure of polymer at temperatures $T<T_{\mathbf{g}}[52]$. 

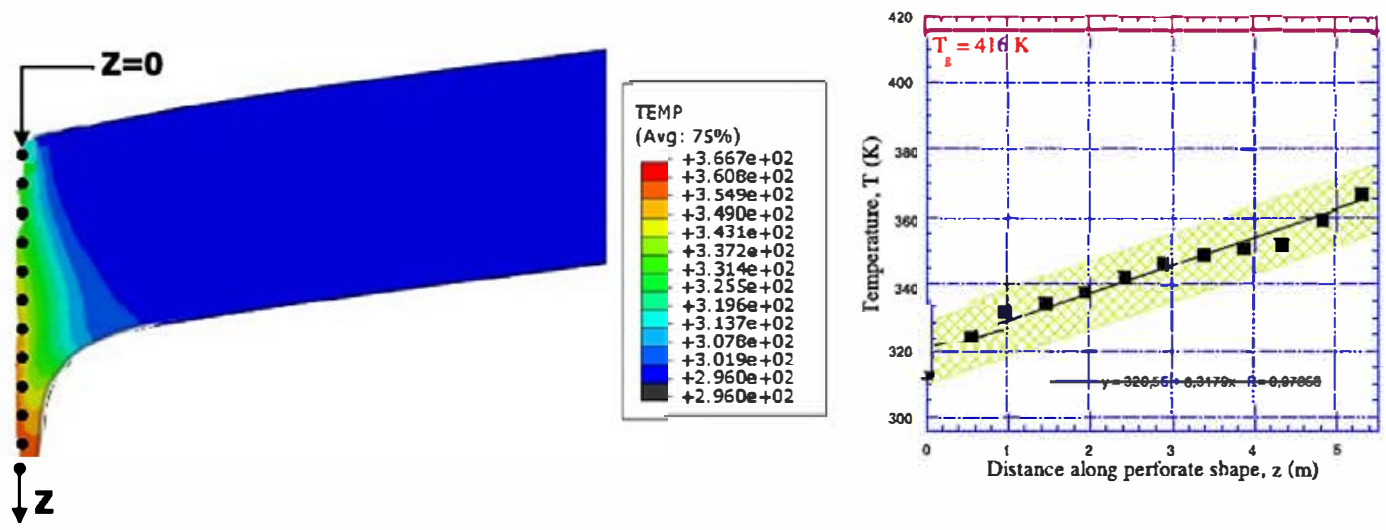

Fig. 16. Numerical predictions of maximum temperature increase in PEEK for impact velocity, $V_{0}=265 \mathrm{~m} / \mathrm{s}$.

\subsection{Numerical simulation}

A good correlation was found between experimental and numerical results, less than $10 \%$, which demonstrates that the models used in this study faithfully reproduce the impact behavior of tested materials, PEEK $450 \mathrm{G}$ and Ti6Al4V, Fig. 15. From numer ical simulations, the maximum temperature increase of PEEK on the contact zone specimen ball has been computed. Therefore, an estimation of the temperature during the process of plastic defor mation has been performed for a velocity corresponding near to the ballistic limit $v_{0} 265 \mathrm{~m} / \mathrm{s}$, Fig. 16. An increase in the temper ature is observed during perforation process. However, for high impact velocity the temperature appears to be lower. The reason is certainly due to the bending effect which induces an increase in plastic work. For high impact velocity the failure appears quickly without bending effect and in this case the plastic work is lower. Generally, the tendency of the temperature is to increase with an average value corresponding to complete failure equal to $\Delta T \approx 100 \mathrm{~K}$. The maximum local temperature has been compared with the glass transition temperature and the melting tempera ture. It is observed that locally the temperature is lower than the glass transition temperature, Fig. 16. This numerical prediction is in agreement with experimental data, where it is observed that the material is still ductile for a temperature $T_{0}<T_{g} 416 \mathrm{~K}$ [11]. Indeed at high impact velocity, no brittle behavior has been observed and PEEK material is capable to absort more energy as velocity increases, Fig. $8 \mathrm{~b}$. Thus it is observed using these numeri cal simulations that the behavior of the material must be well defined since it depends strongly on the temperature sensitivity and strain rate and amplified by large deformation. During this kind of application the strain level observed is higher to 1 .

\section{Conclusions}

The impact behavior of unfilled PEEK was examined through a combination of experiments and finite element simulations. In the full range of impact kinetic energies considered, from $21 \mathrm{~J}$ to $131 \mathrm{~J}$. PEEK material is more efficient for energy absorption in com parison with titanium alloy. During experiments, the material was observed to behave in a ductile manner without evidence of brittle failure and darkening is noticed in highly deformed regions. Finite element simulations of experiments were performed using a plas ticity model typically used for ductile metals. The simulation was in good agreement with the experimental data, confirming the pre dominantly ductile response of PEEK under high strain rate. From numerical simulations, it has been computed the maximum tem perature increase in the perforation process. The numerical predic tions of maximum local temperature are lower than the glass transition temperature of PEEK, in agreement with the ductile behavior observed in impact tests. In conclusion, PEEK appears to be an attractive candidate as matrix material for impact applica tions, implants or to design passive security equipment such as helmets.

\section{Acknowledgements}

The researchers of the University Carlos Ill of Madrid are indebted to Ministerio de Ciencia e Innovación de España (Project DPI/2011 24068) for the financial support received which allowed conducting part of this work. The researchers are indebted to IATI Company for PEEK material supplied. The authors express their thanks to Mr. Sergio Puerta, Mr. David Pedroche and Ms Penelope Miller for their technical support.

\section{References}

[1] Niinomi M. Mechanical biocompatibilities of titanium alloys for biomedical applications. J Mech Behav Biomed 2008;1:30-42.

[2] Rivard $\mathrm{CH}$, Rhalmi S, Coillard C. In vivo biocompatibility testing of peek polymer for a spinal implant system: a study in rabbits. J Biomed Mater Res 2002; 62:488-98.

[3] Horak Z, Pokomy D, Fulin P. Slouf M, Jahoda D, Sosna A. Polyetheretherketone (PEEK), Part I: Prospects for use in orthopaedics and traumatology. Act Ch Ortho Trauma Cechoslovaca 2010;77:463.

[4] Kurtz S, Devine J. PEEK biomaterials in trauma, orthopedic, and spinal implants. Biomaterials 2007:28:4845-69.

[5] Halabi F, Rodriguez J. Rebolledo L Hurtos E, Doblaré M. Mechanical characterization and numerical simulation of polyether-ether-ketone (PEEK) cranial implants. J Mech Behav Biomed 2011;4:1819-32.

[6] Lovald S, Kurtz S. Applications of polyetheretherketone in trauma, arthroscopy and cranial defect repair. In: Kurtz S, editor. PEEK biomaterials handbook. William Andrew Elsevier; 2012. p. 243-60.

[7] Arias A, Rodriguez-Martinez JA, Rusinek A. Numerical simulations of impact behaviour of thin steel plates subjected to cylindrical, conical and hemispherical non-deformable projectiles. Eng Fract Mech 2008:5:1635-56.

[8] Talbot M, Springer G. Berglund I. The effects of crystallinity on the mechanical properties of PEEK polymer and graphite fiber reinforced PEEK. J Compos Mater 1987;21:1056-81.

[9] Sobieraj M, Rimnac C. Fracture, fatigue and noch behavior of PEEK. In: Kurtz S, editor. PEEK biomaterials handbook. William Andrew Elsevier; 2012. p. 61-73.

[10] El-Qoubaa $Z$ Othman R. Characterization and modeling of the strain rate sensitivity of polyetheretherketone's compressive yield stress. Mater Des 2014. htro:ldx doi.oral10.1016 limatdes 2014.10.0807:3-453-469.

[11] Rae P, Brown E, Orler E. The mechanical properties of poly(ether-ether-ketone) (PEEK) with emphasis on the large compressive strain response. Polymer 2007;48:598-615.

[12] Hamdan S, Swallowe G. Crystallinity in PEEK and PEK after mechanical testing and its dependence on strain rate and temperature. J Polym Sci Polym Phys 1996;34:699-705.

[13] Millett J, Boume N, Stevens G. Taylor impact of polyether ether ketone. Int J Impact Eng 2006;32. 1806-1094.

[14] LATI high peiformance thermoplastic. Polyether-ether-ketone material properties, <http://www.lati.com>; 2014.

[15] Sobieraj M, Kurtz S, Rimnac C. Notch sensitivity of PEEK in monotonic tension. Biomaterials 2009;30:6485-94. 
[16] Jonas A, Legras R, Issi JP. Differential scanning calorimetry and infra-red crystallinity determinations of poly(aryl ether ether ketone). Polymer 1991;32(18):3364-70.

[17] Jaekel D, MacDonald D, Kurtz S. Characterization of PEEK biomaterials using the small punch test. J Mech Behav Biomed 2011;4:1275-82.

[18] Karger J, Friedrich K. Temperature and strain-rate effects on the fracture toughness of poly (ether ether ketone) and its short glass-fibre reinforced composite. Polymer 1989;27:1753-60.

[19] Verschueren P, Delye H, Depreitere B, Van Lierde C, Haex B, Berckmans D, et al. A new test set-up for skull fracture characterisation. J Biomech 2007;40:3389-96.

[20] Caccese V, Ferguson J, Edgecomb M. Optimal design of honeycomb material used to mitigate head impact. Compos Struct 2013;100:404-12.

[21] Asgharpur Z, Baumgartner D, Willinger R, Graw M, Peldschus S. The validation and application of a finite element human head model for frontal skull fracture analysis. J Mech Behav Biomed 2013;33:16-23.

[22] Yoganadan N, Pintar N, Sances A, Wals P, Ewing C, Thomas D, et al. Biomechanics of skull fracture. J Neurotraum 1995;12(4):659-68.

[23] Monea A, Van Perre G, Baeck K, Delye H, Verschueren P. The relation between mechanical impact parameters and most frequent bicycle related head injuries. J Mech Behav Biomed 2014;33:3-15.

[24] Arias A, Zaera R, Lopez-Puente JL, Navarro C. Numerical modeling of the impact behavior of new particulate-loaded composite materials. Compos Struct 2003;61:151-9.

[25] Duan Y, Saigal A, Greif R. A uniform phenomenological constitutive model for glassy and semicrystalline polymers. Polym Eng Sci 2001:41:1322-8.

[26] Epee A, Lauro F, Bennani B, Bourel B. Constitutive model for a semi-crystalline polymer under dynamic loading. Int J Solids Struct 2011;48:1590-9.

[27] Colak O, Dusunceli N. Modeling viscoelastic and viscoplastic behavior of high density polyethylene. J Eng Mater Technol 2006;128(4):572-8.

[28] G'Sell C, Jonas J. Determination of the plastic behaviour of solid polymers at constant true strain rate. J Mater Sci 1979;14:583-91.

[29] Boyce M, Arruda E. An experimental and analytical investigation of the large strain compressive and tensile response of glassy polymers. Polym Eng Sci 1990;30(20):1288-98.

[30] Arruda E, Boyce M, Jayachandran R. Effects of strain rate, temperature and thermomechanical coupling on the finite strain deformation of glassy polymers. Mech Mater 1995;19(2-3):193-212.

[31] Regrain C, Laiarinandrasana L, Toillon S, Sai K. Multi-mechanism models for semi-crystalline polymer: constitutive relations and finite element implementation. Int J Plast 2009;25:1253-79.

[32] Johnson GR, Cook WH. A constitutive model and data for metals subjected to large strains high strain rates and high temperatures. In: Proceedings of seventh international symposium ballistics; 1983.

[33] Ghorbel E. A viscoplastic constitutive model for polymeric materials. Int J Plast 2008;24:2032-58.

[34] Louche H, Piette-Coudol F, Arrieux R, Issartel J. An experimental and modeling study of the thermomechanical behavior of an ABS polymer structural component during an impact test. Int J Impact Eng 2009;36:847-61.
[35] Dassault Systèmes Abaqus v6.12 Documentation-ABAQUS analysis user's manual. Abaqus Inc; 2012

[36] Gambirasio L, Rizzi E. On the calibration strategies of the Johnson-Cook strength model: discussion and applications to experimental data. Mater Sci Eng A Struct 2014;610:370-413.

[37] Nasraoui M, Forquin P, Siad L, Rusinek A. Influence of strain rate, temperature and adiabatic heating on the mechanical behaviour of poly-methylmethacrylate: experimental and modelling analyses. Mater Des 2012:37:500-9.

[38] Rittel D. The conversion of plastic work to heat during high strain rate deformation of glassy polymers. Mech Mater 1999;31:131-9.

[39] Bjerke T, Li Z, Lambros J. Role of plasticity in heat generation during high rate deformation and fracture of polycarbonate. Int J Plast 2002;18:549-67.

[40] Pouriayevali H, Arabnejad S, Guo Y, Shim V. A constitutive description of the rate-sensitive response of semi-crystalline polymers. Int J Impact Eng 2013;62:35-47.

[41] Mourad A, Elsayed H, Barton D, Kenawy M, Abdel-Latif L. Ultra high molecular polyethylene deformation and fracture behaviour as a function of high strain rate and triaxial state of stress. Int J Fract 2003;120:505-15.

[42] Johnson GR, Cook WH. Fracture characteristics of three metals subjected to various strains, strain rates, temperatures and pressures. Eng Fract Mech 1985;21(1):31-48.

[43] Cheng J, Nemat-Nasser S. A model for experimentally-observed high-strainrate dynamic strain aging in titanium. Acta Mater 2000;48:3131-44.

[44] Khan Akhtar S, Suh Yeong Sung, Kazmi Rehan. Quasi-static and dynamic loading responses and constitutive modeling of titanium alloys. Int J Plast 2004;20(12):2233-48.

[45] Wang X, Shi J. Validation of Johnson-Cook plasticity and damage model using impact experiment. Int J Impact Eng 2013;60:67-75.

[46] Rusinek A, Rodríguez-Martínez J, Zaera R, Klepaczko J, Arias A, Sauvelet C. Experimental and numerical study on the perforation process of mild steel sheets subjected to perpendicular impact by hemispherical projectiles. Int J Impact Eng 2009;36(4):565-87.

[47] Borruto A. A new material for hip prosthesis without considerable debris release. Med Eng Phys 2010;32:908-13.

[48] Recht RF, Ipson TW. Ballistic perforation dynamics. J Appl Mech 1963:30:384-90.

[49] Nasiri-Abarbekoh H, Ekrami A, Ziaei-Moayyed A, Shohani M. Effects of rolling reduction on mechanical properties anisotropy of commercially pure titanium. Mater Des 2012;34:268-74.

[50] Bless S, Jurick D. Design for multi-hit capability. Int J Impact Eng 1998;10:905-8.

[51] Swallowe GM, Fernandez JO, Hamdan S. Crystallinity increases in semi crystalline polymers during high rate testing. J Phys IV France $1997 ; 7(3): 453-8$

[52] Sobieraj M, Kurtz S, Rimnac C. Large deformation compression induced crystallinity degradation of conventional and highly crosslinked UHMWPEs. Biomaterials 2005;26:6430-9. 